\title{
COMPLEXO AGROINDUSTRIAL DE PRODUÇÃO E FABRICAÇÃO DO SUCO CONCENTRADO DE LARANJA
}

\author{
AGRO-INDUSTRIAL COMPLEX FOR THE PRODUCTION AND MANUFACTURE OF \\ ORANGE CONCENTRATED JUICE
}

Guilherme Gabriel de Lima Mazochi-guimazochi@outlook.com Faculdade de Tecnologia de Taquaritinga - Taquaritinga - São Paulo - Brasil

Roberto Hirochi Okada - okada_roberto_hirochi@hotmail.com Faculdade de Tecnologia de Taquaritinga - Taquaritinga - São Paulo - Brasil

DOI: 10.31510/infa.v18i1.1100

Data de submissão: 14/04/2021

Data do aceite: 09/07/2021

Data da publicação: 30/07/2021

\begin{abstract}
RESUMO
O presente trabalho tem como objetivo apresentar síntese sobre a produção e fabricação de suco concentrado de laranja, em âmbito nacional e internacional, uma vez que o Brasil se destaca como um líder mundial do ramo. Neste trabalho, também, são encontradas abordagens sobre os processos de produção do suco de laranja, produtos produzidos através da laranja, com análise química e física, normas regulamentadoras e como estas influenciam nas situações mercadológicas. Por fim, são apresentadas as considerações finais acerca do tema, como, a importância do Brasil como o maior produtor e exportador mundial e quais regiões desempenham um importante papel produtivo para o país. Este estudo baseia-se em pesquisas descritivas e exploratórias, objetivando elucidar sobre a importância do papel da citricultura para o desenvolvimento econômico do país.
\end{abstract}

Palavras-chave: Suco. Laranja. Exportação. Produção. Economia.

\begin{abstract}
The present work aims at a synthesis on the production and manufacture of concentrated orange juice, in national and international scope, where Brazil stands out as a world leader in the field. In this work, also, approaches are found on the production processes of orange juice, products produced through orange, with chemical and physical analysis, regulatory standards and how, the importance of Brazil as the world's largest producer and exporter and which regions make an important productive role for the country they influence in market situations. Finally, the final considerations on the theme are presented. This study is based on descriptive and exploratory research, aiming to elucidate the importance of the role of citrus in the country's economic development.
\end{abstract}


Keywords: Juice. Orange. Export. Production. Economy.

\section{INTRODUÇÃO}

É notório que a laranja é um produto de grande importância para a agricultura nacional e contribui para o desenvolvimento da economia brasileira, principalmente pela performance na produção e exportação de suco concentrado.

Segundo a CitrusBR, Associação nacional dos exportadores de sucos cítricos (2020), em termos de exportação, o Brasil é destaque no cenário mundial, mesmo com a concorrência de potências econômicas como China, Estados Unidos e União Europeia

A CitrusBR, ainda pondera que mesmo em meio à crise causada pela pandemia de Covid-19, o país registrou em abril de 2020 um aumento de $17 \%$ no número de exportações em comparação à safra anterior.

Neves et. al. (2014), mostra que o país detém 53\% da produção global de suco de laranja, tendo o estado de São Paulo e o Triângulo Mineiro como as regiões que mais contribuem para estes números. Estes dados demonstram a importância e a grandeza do setor para o país, seja para o mercado externo quanto para o mercado interno.

Ainda sobre o estudo, Neves et.al. (2014) destaca que o consumo de laranja, além de produtos que são extraídos da fruta são muito relevantes para as famílias e estabelecimentos locais. Estes representam cerca de $30 \%$ do consumo da produção nacional.

O objetivo geral deste artigo é apresentar um estudo baseado na produção nacional de suco de laranja concentrado, apontando as principais características que tornam, esta, em uma das mais importantes atividades econômicas do Brasil e fonte de renda para negócios e famílias. Elucidando sobre a história da citricultura brasileira, o cenário agrícola atual.

Artigo este que tem como base de pesquisa artigos, livros, revistas e sites presentes na internet.

\section{HISTÓRIA MUNDIAL DO SUCO DE LARANJA}

Fernandes (2010) afirma que uma das árvores mais conhecidas e estudadas do mundo, a laranjeira destaca-se por sua alta capacidade frutífera. Esta espécie, mesmo em meio a controvérsias sobre a origem exata, é originária da Ásia. 


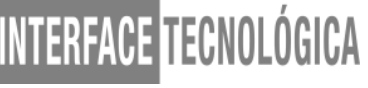

Segundo Junior et al. (2005), as plantas de gênero Citrus são originárias das regiões subtropicais e tropicais do sudeste e sul asiático. Estas foram levadas para a Europa na época das Cruzadas e logo após vieram para o Brasil no século XVI.

Já Donadio, Filho e Moreira (2005) afirma que os primeiros registros sobre árvores cítricas e seu cultivo surgiram entre 1.027 e 256 A.C., registros estes encontrados em publicações chinesas que apontam que a primeira laranja doce encontrada pertencia à espécie das tangerinas, conhecidas como tien kan. O estudo ainda cita que a sua distribuição mundial se deu pelo escambo com animais e outras plantas presentes na região, o que causou uma mutação da fruta para como a conhecemos atualmente.

Donadio (op. Cit.) ainda explicar que as primeiras sementes da espécie foram trazidas para o continente americano por Cristóvão Colombo em meados de 1493 e décadas depois ao Brasil logo após a sua colonização, por volta de 1530.

\subsection{História do suco de laranja no Brasil}

O clima tropical e a qualidade do Brasil favoreceram a rápida adaptação e expansão por todo o território nacional.

Para Fernandes (2010), esta expansão permitiu o surgimento de uma variação com mudas enxertadas da fruta em Salvador, no estado da Bahia, e tão logo foi nomeada como laranja baiana.

Segundo Neves (2014), a primeira fábrica de suco de laranja não concentrado fora instalada durante a Segunda Guerra Mundial com o objetivo de evitar o desperdício da fruta e isso não impediu que a recente empresa fosse à falência. Mas com uma forte geada que atingiu a Flórida na década de 60, surgiu a oportunidade de o Brasil exportar o produto, além de abastecer o mercado interno.

Atualmente, o Brasil destaca-se no cenário mundial, sendo considerado o maior exportador de suco de laranja e tendo o estado de São Paulo como o maior produtor.

Minke (2020a) aponta que na safra agrícola 2018/2019 foram colhidas mais de 13,6 mil toneladas de laranja, uma produção 5\% maior que a safra anterior 2017/2018. 


\subsection{A variedade dos pomares de laranja}

A variedade dos pomares citrícolas é de suma importância para a colheita em várias épocas do ano.

Segundo Neves (2014) a variedade é importante para evitar concentração de oferta em somente um período ao longo do ano. Além da possibilidade de negociar sua produção em época de preços maiores, permite à indústria um prolongamento do tempo para processar a laranja para a produção de suco concentrado.

Esta variedade nos pomares também é benéfica para evitar pragas e doenças que possam prejudicar o rendimento da produção.

Neves (op. Cit.) ainda destaca que a variedade proporciona otimização no controle de doenças e pragas, além de reduzir possíveis impactos de adversidades climáticas.

\subsection{Pragas e doenças que podem comprometer a plantação}

A presença de doenças e pragas é muito comum e podem influenciar diretamente no rendimento da colheita.

Neves (2014) alerta que de 2000 a 2009, cerca de 4 doenças, estas nomeadas Cancro Cítrico, CVC, Morte Súbita e Greening foram responsáveis pela morte de mais de 39 milhões de árvores no estado de São Paulo e Minas Gerais.

Donadio, Filho e Moreira (2005) afirmam que outras doenças comumente encontradas nas plantações são causadas por fungos, como a verrugose, gomose, melanose, rubelose e mancha preta, e pragas como ácaros, pulgões, formigas e outras mais.

\subsection{Qualidade do solo brasileiro no plantio}

As laranjeiras possuem fácil adaptação em regiões com grande variação térmica, mas perdem a sua capacidade produtiva.

Para Carmargo et. al. (1991) temperaturas acima de $40^{\circ} \mathrm{C}$ e abaixo de $13^{\circ} \mathrm{C}$ faz com que a produção seja de má qualidade devido à baixa taxa de fotossíntese.

Outro fator que influencia diretamente na qualidade produtiva do fruto está associado à qualidade do solo. 
Segundo Junior et al. (2005) as condições ideais para o desenvolvimento das árvores e frutos se dá em solos mais úmidos e profundos, contendo um $\mathrm{pH}$ entre 5,0 e 6,5. O autor ainda afirma que em solos arenosos em que a absorção de água é menor ou em terrenos com condições de encharcamento são desfavoráveis para o plantio.

Em relação às condições climáticas, Camargo et al. (1999) cita que as condições climáticas predominantes no estado de São Paulo podem influenciar no plantio e rendimento de árvores que fornecem citros, devido às variações meteorológicas que favorecem o crescimento inicial do fruto.

\section{PROCESSOS DE PRODUÇÃO DE SUCO DE LARANJA}

Para Corrêa (2010), a cadeia produtiva do agronegócio brasileiro é constituída de inúmeras atividades que vão desde o plantio até a pós-venda, passando pelo plantio, negociação, marketing, distribuição e armazenamento.

Antes mesmo da do processo de fabricação, destaca-se o plantio e a utilização da tecnologia para controle e qualidade para otimização e prevenção contra doenças e pragas.

Portugal (1998) ainda destaca que são processos que se conectam e se iniciam com os fornecedores de insumos e chegam até o consumidor final.

Apesar da importância e do tamanho do mercado citrícola no Brasil, o país ainda não possui normas regulamentadoras específicas para este setor, tendo sua regulamentação atrelada ao Ministério da Agricultura, Pecuária e Abastecimento (MAPA, 2011).

\subsection{Preparo do solo e plantio}

Segundo Casali et al. (2016), para maior qualidade na produção agrícola, seja ela empresarial ou familiar, são de fundamental importância a análise do solo, identificação da presença de resíduos provenientes de plantas de cobertura e dos resíduos culturais e de culturas comerciais deixados no solo.

Para Araujo (2017) as plantas de cobertura possuem uma função essencial para a melhoria na qualidade do solo, química e biologicamente, devido à matéria orgânica que contribuem para a fertilidade. 


\subsection{A colheita e a geração de empregos}

Para Nascimento, Cuzin e Martins (2006) as técnicas de colheita utilizadas influenciam diretamente nas condições fisiológicas e na qualidade da utilização do fruto in natura, o que resulta em uma depreciação do seu valor comercial.

Para Oliveira e Cereda (1999) são consideradas algumas técnicas para evitar possíveis perdas no valor comercial do fruto como controle de temperatura, umidade e aplicação de ceras.

O setor tem grande papel na geração de empregos por todo o país, principalmente no estado de São Paulo e Triângulo Mineiro.

Segundo Minke (2020b) somente em 2019 foram colhidas 385 milhões de caixas de laranja ao longo da safra, totalizando aproximadamente 96 bilhões de laranjas colhidas manualmente.

\subsection{A tecnologia na indústria}

O Brasil é o maior exportador de suco concentrado de laranja do mundo e para atender a esta demanda, faz-se necessário o aprimoramento das técnicas de processamento do setor.

Segundo a CitrusBR (2020), o país registrou um aumento nas exportações de 17\% na safra 2019/2020, registrando aproximadamente 1.4 bilhão de dólares.

Sobre o mercado concentrados, Furtado, Carvalho e Rauen (2011) explica que o setor é capaz de gerar inovações tecnológicas buscando o ganho em eficiência e competitividade em relação a outros mercados, por isso há constante aprimoramento de técnicas de avaliação de resultados.

A inovação nas processadoras teve um grande avanço no início da década de 90 , baseando-se na tecnologia principalmente encontrada nos Estados Unidos.

Gaban (2008) afirma que as indústrias adotaram sistemas integrados de transporte, inovações no sistema de estocagem do suco e na logística através de investimentos em portos.

Segundo Minke (2020a) atualmente a maior parte do suco de laranja concentrado e não concentrado destinado à exportação é produzido pelas processadoras localizadas no estado de São Paulo. 


\section{MATÉRIAS-PRIMAS}

\subsection{Laranja}

Segundo Filho (2005), trata-se de uma fruta a qual sofreu mutações as quais resultaram em variações que se adaptam em diferentes condições climáticas. Esta fruta é constituída por casca, suco, polpa, membrana e sementes. Componentes responsáveis pela coloração, aroma, suco e proteção.

\section{2 Água}

Segundo Coelho (2013) há evaporação da água durante a produção, produzida na etapa de concentração de suco. Em seguida é separada por um processo de condensação do vapor, este vindo a ser aproveitado em outras atividades dentro das indústrias.

Tocchini et al. (1995) ainda afirma que o suco concentrado é depositado em um evaporador a vácuo e nesta etapa é aquecido a uma temperatura de $90^{\circ} \mathrm{C}$ por aproximadamente 40 segundos com o objetivo de inativar pectinolíticos.

\subsection{Hipoclorito de sódio}

Trata-se de um composto químico sendo usado como agente sanitizante ou alvejante, de fórmula $\mathrm{NaCIO}$.

Para Bueno et al. (2016) a solução presente na água sanitária é o hipoclorito de sódio, obtido através de uma reação química com o cloro com o hidróxido de sódio. Isso é possível após a dissociação entre cátion de sódio através de uma reação de oxidação-redução entre o ânion hipoclorito e vestígios de manchas.

Tal processo é resultado da dissociação entre hipoclorito de sódio e o cátion sódio após uma reação química de oxidação e reação entre o ânion-hipoclorito e as manchas a serem removidas.

Bueno (op. Cit.) ainda afirma que é possível a preparação do hipoclorito de sódio através da absorção do gás cloro em solução de hidróxido de sódio se mantido a temperaturas inferiores a $40^{\circ} \mathrm{C}$. 


\section{ETAPAS DO PROCESSAMENTO DO SUCO DE LARANJA}

\subsection{Análise das frutas}

No processo de seleção de frutas com condições para a produção, alguns aspectos são avaliados como cor, tamanho e forma.

Segundo Chitarra e Chitarra (1990), a coloração da laranja nem sempre pode ser um aspecto de exata certeza, podendo ocultar falhas características ou na maturação interna, mesmo que externamente a coloração não seja tão próxima à cor alaranjada.

Para Reis et al. (2000), condições climáticas influenciam nas características da coloração da casca, o que pode comprometer a colheita e a posterior seleção do fruto mesmo em ideais condições.

Chitarra e Chitarra (1990) afirmam que o processo de maturação é caracterizado pela redução da taxa de crescimento do fruto, com isso há uma mudança na coloração devido à degradação de enzimas da clorofila e dos carotenoides. Etapa em que há aumento de açúcares e aminoácidos.

\subsection{Extração do suco}

Segundo Munhoz e Morabito (2009), o processo de extração do suco é iniciado com a emulsão de água e óleo, juntamente com fragmentos da casca da fruta. Após este procedimento, o resultado é transportado para o setor responsável pela produção de óleo essencial, passando por peneiramento junto com o bagaço com o objetivo de retirar a maior quantidade possível de água e óleo.

Munhoz e Morabito (op. Cit.) ressaltam que enquanto o óleo é tratado para retirada de cera, a polpa é encaminhada para o setor de filtragem e centrifugação para retirar o restante do suco ajuste do teor da polpa.

Tocchini et al. (1995) afirma que a extração é feita em unidades com recursos para compressão do fruto integral. Isso permite que o suco saia por um cilindro de modo a impedir a incorporação de materiais indesejados. 


\subsection{Pasteurização}

Neto e Faria (2003) citam que a crescente procura pelo suco de laranja se deu pela procura de produtos mais saudáveis para substituir bebidas industrializadas. Esta demanda foi atendida com o suco de laranja pasteurizado que passa por tratamentos térmicos mais leves com o objetivo de manter o sabor próximo ao do produto fresco.

Sobre a pasteurização Jogen (2002) conceitua que se refere a um tratamento térmico moderado que tem como objetivo central eliminar microrganismos e inativar enzimas. $\mathrm{O}$ processo não chega a eliminar esporos e o seu armazenamento deve ser refrigerado para manter as propriedades sensoriais.

\subsection{Evaporação}

A evaporação é uma das técnicas mais utilizadas para efetuar a concentração de sucos. Este processo exige etapas como seleção, classificação e armazenamento.

Segundo Machado (2010) para realizar o processo de concentração, o suco passa por vários estágios nos evaporadores onde a temperatura é elevada gradativamente.

Existem alguns modelos de evaporadores, como o de tubos horizontais que são de tecnologia mais antiga. Outro modelo de grande usabilidade nas indústrias são os verticais, usados também na produção de outros implementos como leite e açúcar.

\section{METODOLOGIA}

O presente trabalho é de caráter descritivo e exploratório, com o objetivo de abordar toda a cadeia produtiva do suco concentrado de laranja e a sua importância econômica e mercadológica. Para que isso, foram usadas referências de inúmeros autores através de livros, artigos, revistas e sites. Com isso foi traçado um panorama geral, de cada etapa do processo de fabricação do suco. 


\section{CONCLUSÃO}

Concluiu-se que a laranja tem um papel fundamental em nossa história. Fruta essa de origem asiática e que toda a sua trajetória do país veio acompanhada de inovação aprimoramento das técnicas de produção. $\mathrm{O}$ artigo mostra que os cuidados com a fruta se iniciam antes mesmo do plantio, com os devidos cuidados com o solo até a etapa que abrange o consumidor final, seja ele no mercado interno ou externo.

No caso mercado externo, o país destaca-se como o maior produtor e exportador de suco concentrado de suco de laranja, à frente de outros países economicamente maiores que o Brasil como Estados Unidos e China.

E no mercado interno, o estado de São Paulo, seguido pelo Triângulo Mineiro, são as principais regiões produtoras do país.

\section{REFERÊNCIAS}

ARAUJO, C. Artigo - Plantas de cobertura: O que é isto?. Empresa Brasileira de Pesquisa Agropecuária. 25 de set. 2017. Disponível em: <https://www.embrapa.br/busca-de-noticias//noticia/28512796/artigo---plantas-de-cobertura-o-que-eisto\#: :text=naturais $\% 20 \mathrm{n} \% \mathrm{C} 3 \% \mathrm{~A} 3 \mathrm{o} \% 20$ renov $\% \mathrm{C} 3 \% \mathrm{~A} 1$ veis.,As\%20plantas\%20de \%20cobertura $\% 20$ quando $\% 20$ adequadamente $\% 20$ utilizadas $\% 20$ se $\% 20$ constituem $\% 20 \mathrm{em}$, comp $\% \mathrm{C} 3 \% \mathrm{~B} 5 \mathrm{em} \% 20 \mathrm{a} \% 20$ fertilidade $\% 20 \mathrm{do} \% 20$ solo.>. Acesso em: $08 / 01 / 2021$.

BUENO, B. O. et. al. Produção de suco de laranja concentrado. 2016. 27 p. TCC (Ensino Técnico em Química). Curitiba. Disponível em: $<$ http://www.ceepcuritiba.com.br/wpcontent/uploads/2019/05/Producao-de-suco-de-laranja-concentrado.pdf $>$. Acesso em: $13 / 01 / 2021$.

CAMARGO, M. P. B.; ORTOLANI, A. A.; PEDRO JÚNIOR, M. J.; ROSA, J. M. Modelo agrometeorológico de estimativa para a cultivar de laranja Valência. Bragantia, Campinas, v. 58, n.1, p 171-178, 1999.

CASALI, C.A. et al. Benefícios do uso de plantas de cobertura de solo na ciclagem de fósforo. In: TIECHER, T. (Ed.) Manejo e conservação do solo e da água em pequenas propriedades rurais no sul do Brasil: práticas alternativas de manejo visando a conservação do solo e da água. Porto Alegre, RS: UFRGS, 2016. p. 23-33. 
CORRÊA, L. H. Gestão de Redes de Suprimento - Integrando Cadeias de Suprimento No Mundo Globalizado. 1 ed. São Paulo: Atlas, pág. 112, 2010.

CITRUS BR. Exportações de suco de laranja fecham safra em alta. 2020. Disponível em: $<$ https://citrusbr.com/noticias/exportacoes-de-suco-de-laranja-fecham-safra-em-alta/ $>$. Acesso em: 20 nov. 2020.

CHITARRA, M.I.F; CHITARRA, A.B. Pós-colheita de frutos e hortaliças: fisiologia e manuseio. Lavras: ESAL/FAEPE, 1990. 320p.

COELHO, A. Viabilidade técnica e econômica do aproveitamento para consumo humano da água evaporada na industrialização de suco de laranja concentrado. 2013. Disponível em:

$<$ http://repositorio.unicamp.br/jspui/bitstream/REPOSIP/256792/1/Coelho_AlbaLuciaAndrad e_D.pdf $>$. Acesso em: 08/01/2021.

DONADIO, L. C.; FILHO, F. A. A. M.; MOREIRA, C. S. Centros de origem, distribuição geográfica das plantas cítricas e histórico da citricultura no Brasil. In: MATTOS JÚNIOR, D.; DE NEGRI, J. D.; PIO, R. M.; POMPEU JÚNIOR, J. (Ed.). Citros. Campinas: Instituto Agronômico e Fundag, 2005. p.1-18.

FERNANDES, B.C.Desenvolvimento histórico da citricultura brasileira. Orientador: Sergio Gertel. 2010. 49 p. Monografia (Graduação em Ciências Econômicas) -UNESP, Araraquara, 2010. Disponível em:

$<$ https://repositorio.unesp.br/bitstream/handle/11449/118999/fernandes_bc_tcc_arafcl.pdf?seq uence $=1 \&$ isAllowed $=\mathrm{y}>$. Acesso em: 07/ 01/2021.

FILHO, W. G. V. Tecnologia de bebidas: matéria prima, processamento, BPF/APPCC, legislação e mercado. São Paulo, SP, pág.550, 2005.

FURTADO, A. T.; CARVALHO, R. Q.; RAUEN, A. T. Inovação tecnológica no setor empresarial

paulista: uma análise com base nos resultados da Pintec. In: Tecnologia e Sociedade: transformações sociais. Ed: UTFPR, pp.189-236, 2011.

GABAN, L. C. Análise comparativa das instituições e organizações agroindustriais citrícolas

dos estados da Flórida (EUA) e São Paulo (Brasil. 2008. 191p. Dissertação (Mestrado em Engenharia de Produção) - Universidade Federal de São Carlos, UFSCar, São Carlos, 2008. 
JUNIOR, D.et al. CITROS: principais informações e recomendações de cultivo. Instituto Agronômico de Campinas, 17 de mar. de 2005. Disponível em: <

http://www.iac.sp.gov.br/imagem_informacoestecnologicas/43.pdf $>$ Acesso em: 05/01/2021.

JOGEN, W., Fruit and Vegetable Processing - Improving Quality, Washington: CRC Press, 2002. 397 p.

MACHADO, T. V. Avaliação sensorial e físico-química do suco de laranja proveniente das etapas do processamento do suco concentrado e congelado. 2010. Dissertação (Mestrado em Ciências dos Alimentos) - Faculdade de Ciências Farmacêuticas, Universidade Estadual Paulista "Júlio de Mesquita Filho", São Paulo, 2010.

MINISTÉRIO DA AGRICULTURA, PECUÁRIA E ABASTECIMENTO (MAPA). agenda estratégica: Citricultura. Brasília: Assessoria de Comunicação Social, 2011. Disponível em: $<$ http://www.agricultura.gov.br/assuntos/camaras-setoriaistematicas/agendas/arquivos/citricultura.pdf $>$. Acesso em: 08/01/2021.

MINKE, P. aMaior produtor de laranja e exportador de suco de laranja do mundo, SP deve manter setor ativo para atender demanda pela fruta rica em vitamina $C$.

Agricultura e Abastecimento do Governo do Estado de São Paulo, 30 de mar. de 2020.

Disponível em: <https://agricultura.sp.gov.br/noticias/maior-produtor-de-laranja-eexportador-de-suco-de-laranja-do-mundo-sp-deve-manter-setor-ativo-para-atender-demandapela-fruta-rica-em-vitamina-c/> Acesso em: 07/01/2021.

MINKE, P. b Citricultura gerou mais de 48 mil novas vagas de emprego em 2019. Agricultura e Abastecimento do Governo do Estado de São Paulo, 3 de fev. de 2020. Disponível em: <https://agricultura.sp.gov.br/noticias/citricultura-gerou-mais-de-48-milnovas-vagas-de-emprego-em-2019/>. Acesso em: 09/01/2021.

MUNHOZ, J. R.; MORABITO, R. Otimização no Planejamento Agregado de Produção em Indústrias de Processamento de Suco Concentrado Congelado de Laranja, 2009. Disponível em: < http://www.dep.ufscar.br/docentes/morabito/joserenato_gp09.pdf $>$. Acesso em: 03/01/2021.

NASCIMENTO, L. M.; CUZIN, J.; MARTINS, A. B. G. Efeito do Etileno na Qualidade de Frutos da Laranjeira Pera Armazenados sob Diferentes Temperaturas. Revista Iberoamericana de Tecnológia Postcosecha, Sonora, v. 8, n. 1, p. 7-16, 2006.

NEVES, M.F.et al. O Retrato da Citricultura Brasileira. 1. ed. São Paulo: Markestrat, 2014. 138 p. Disponível em: 
$<$ http://www.citrusbr.com/download/Retrato_Citricultura_Brasileira_MarcosFava.pdf $>$. Acesso em 03/01/2021.

NETO, R. S., FARIA, J. A. F., Alterações químicas e enzimáticas em suco de laranja pasteurizado. Higiene Alimentar, 2003, vol.17, nº114/115, p. 60-67.

OLIVEIRA, M. A.; CEREDA, M. P. Efeito da Película de Mandioca na Conservação de Goiabas. Brazilian Journal of Food Technology, 1999. Disponível em:

$<$ https://www.scielo.br/pdf/bjft/v17n2/a10v17n2.pdf > . Acesso em: 15/01/2021.

PORTUGAL, A. D. A importância estratégica da prospecção tecnológica para o SNPA. In: Cadeias produtivas e sistemas naturais, prospecção tecnológica. Editores. Castro etal. Brasília: Embrapa-SPI / Embrapa DPD, pág. 11-17. 1998.

REIS, J.M.R. et al. Relação entre o grau de coloração da casca e algumas características de qualidade de tangerina "Ponkan". Ciência e Agrotecnologia. Lavras, v.24 p.182, 2000.

TOCCHINI, R. P.; NISIDA, A. A. C.; DE MARTIN, Z. J. Industrialização de polpas, sucos e néctares de frutas, pág.85. 1995.

VIEIRA, SÉRGIO. Sem isolamento para a laranja brasileira. Dinheiro Rural, 08 de jun. de 2020. Disponível em: $<$ https://www.dinheirorural.com.br/sem-isolamento-para-a-laranjabrasileira> Acesso em: 05/01/2021. 